\title{
The WorldRisklndex 2016: Reveals the Necessity for Regional Cooperation in Vulnerability Reduction
}

\author{
Joern Birkmann* and Torsten Welle \\ University of Stuttgart, Institute of Spatial and Regional Planning \\ *Joern.birkmann@ireus.uni-stuttgart.de
}

Published 18 November 2016

\begin{abstract}
Extreme events do not necessarily trigger extreme impacts. Exposure and vulnerability levels often decide whether hazards and extreme events lead to disasters or severe suffering or not. Measuring and assessing different levels of exposure, vulnerability and risk is therefore crucial in order to inform decision making and to provide guidance for defining priorities for risk reduction and adaptation. The WorldRiskIndex (WRI) is an approach to assess global exposure, vulnerability and risk patterns based on national scale resolution data. The new results of the WRI 2016 underscore that risk of natural hazards and climate change is particularly high in Oceania, Southeast Asia, Sub-Saharan Africa and the Caribbean as well as Central America. The assessment for 171 countries reveals important improvements in some countries, such as Namibia, however, in other countries such as Brunei, Darussalam and Serbia risk has increased, particularly due to higher susceptibility and lower coping and adaptive capacities to deal with extreme events and natural hazards. The analysis of global patterns of risk shows that not only the physical exposure to extreme events or natural phenomena but also the societal context conditions in countries like Vanuatu, Niger, Haiti and Afghanistan are key drivers of risk and therefore efforts for risk reduction and adaptation at the local and national level need to also address aspects such as poverty and corruption. The persistence of high risk in various countries in Africa and Oceania also suggests that it is likely that these countries might not be able to effectively reduce risks solely on their own but rather need regional approaches and institutions for risk reduction and adaptation.
\end{abstract}

Keywords: WorldRiskIndex; Vulnerability; Risk Reduction; Regional Cooperation; Adaptation.

This is an Open Access article published by World Scientific Publishing Company. It is distributed under the terms of the Creative Commons Attribution 4.0 (CC-BY) License. Further distribution of this work is permitted, provided the original work is properly cited. 


\section{Introduction}

Analyzing, assessing and communicating risks triggered by natural hazards and climate change are important prerequisites for effective risk reduction and adaptation strategies as well as for empowering responses (Mach et al. 2016; Queiroz de Almeida et al. 2016).

In this regard, the WorldRiskIndex (WRI) is a mathematical model and a visualization and communication tool that systematically combines the physical and spatial exposure to extreme natural events and societal vulnerability in risk values and charts. The index has been developed by Birkmann and Welle in close cooperation with colleagues from the United Nations University and practitioners of the Alliance Development Works. The first edition of the WRI has been released in 2011 (see Birkmann et al. 2011) and since then it has been published annually in the WorldRiskReport. That means the index is part of the WorldRiskReport that has different thematic foci each year. The WRI 2016 is based on the analysis of 28 indicators assessing global risk patterns for 171 countries, since for other countries or small island states, such as Somalia, North Korea or the Maldives not sufficient and reliable data were existing to calculate the WRI. This allows statements on potentially threatened areas or countries and the likelihood of severe problems and challenges in dealing with it for example in terms of limited coping and adaptive capacities (see Birkmann et al. 2011; Welle and Birkmann 2015a,b). The individual dimensionless index values are transformed into a geo-information system (GIS) and are represented in maps. Even though some data requires improvement, the overall patterns of global risk distributions and respective hotspots are reasonable and the overall indicator system and results are statistically valid.

The comparison of 171 countries can provide decision makers as well as various actors involved in risk reduction and adaptation, media and the general public with a first information layer. Specific programs and risk reduction policies at national, provincial or local level do, however, require additional information. For its function of comparing countries on a global scale, the index has to be based on globally available and accessible data. Compared to in-depth local studies or provincial assessment which we also conducted within the last years, the WRI does achieve high visibility in the global media and has even been used in political discussions, for example by representatives in the National Parliament of the Philippines, as an argument for more funding of disaster risk reduction.

In some cases, the WRI is misinterpreted. The index does not allow forecasting of the next disaster or any specific disaster event. It rather demonstrates that risks in the context of natural hazards and climate change are not solely a product of the natural phenomena (e.g., flood, storm or sea-level rise), but rather the result of the 
interaction between natural phenomena and extreme events on the one hand and human and infrastructure vulnerability on the other. That means whether an extreme event leads to extreme impacts and even to a disaster is not only determined by the magnitude and intensity of the extreme event as such but by the question how vulnerable a community, society or infrastructure is to such impacts. In this context the concept of the index is also comparable with a standard risk definition and equation that aim to measure risk by examining the likelihood, intensity and severity of the stressor or hazard with the potential negative consequences (e.g., loss of life, economic loss, etc.) or the damages that it might trigger. In our view the potential negative consequences should not just be assessed in economic terms, but should capture the multifaceted nature of vulnerability (social, ecological and economic aspects of vulnerability). Against this background, the index is meant to give answers to the following questions:

- How many people are on average annually exposed to natural hazards and potential impacts of sea-level rise?

- How susceptible are people who are exposed to natural hazards and extreme events?

- Which level of preparedness and capacities exist in different countries to enable people to cope with or adapt to natural hazards and extreme events?

- Where are global hotspots of exposure to natural hazards and hotspots of vulnerability?

- How do global risk patterns look like?

\section{Components of the WRI and the Link to the SDGs}

The WRI consists of four components: exposure (specifically, exposure to natural hazards), susceptibility, coping capacities and adaptive capacities (Birkmann et al. 2011; Welle and Birkmann 2015b; Welle et al. 2014). The Index as a whole is based on 28 indicators using data that is available and accessible worldwide (see Table 1). Various indicators also represent and refer to the 17 U.N. Sustainable Development Goals (SDGs) and are, in part, even recommended for the monitoring of the implementation of the SDGs and the targets defined by the international community (see United Nations 2015). With regard to content, 22 indicators of the WRI are linked to 10 goals of the SDGs (see Table 2).

Consequently, the WRI is also providing information where SDGs will be difficult to achieve within a global comparison. Against the background of the new results of the WRI, one can even argue that it is worth to explore whether global targets such as the SDGs should be differentiated for various regions and their specific challenges, considering existing adaptation and risk reduction deficits. The 


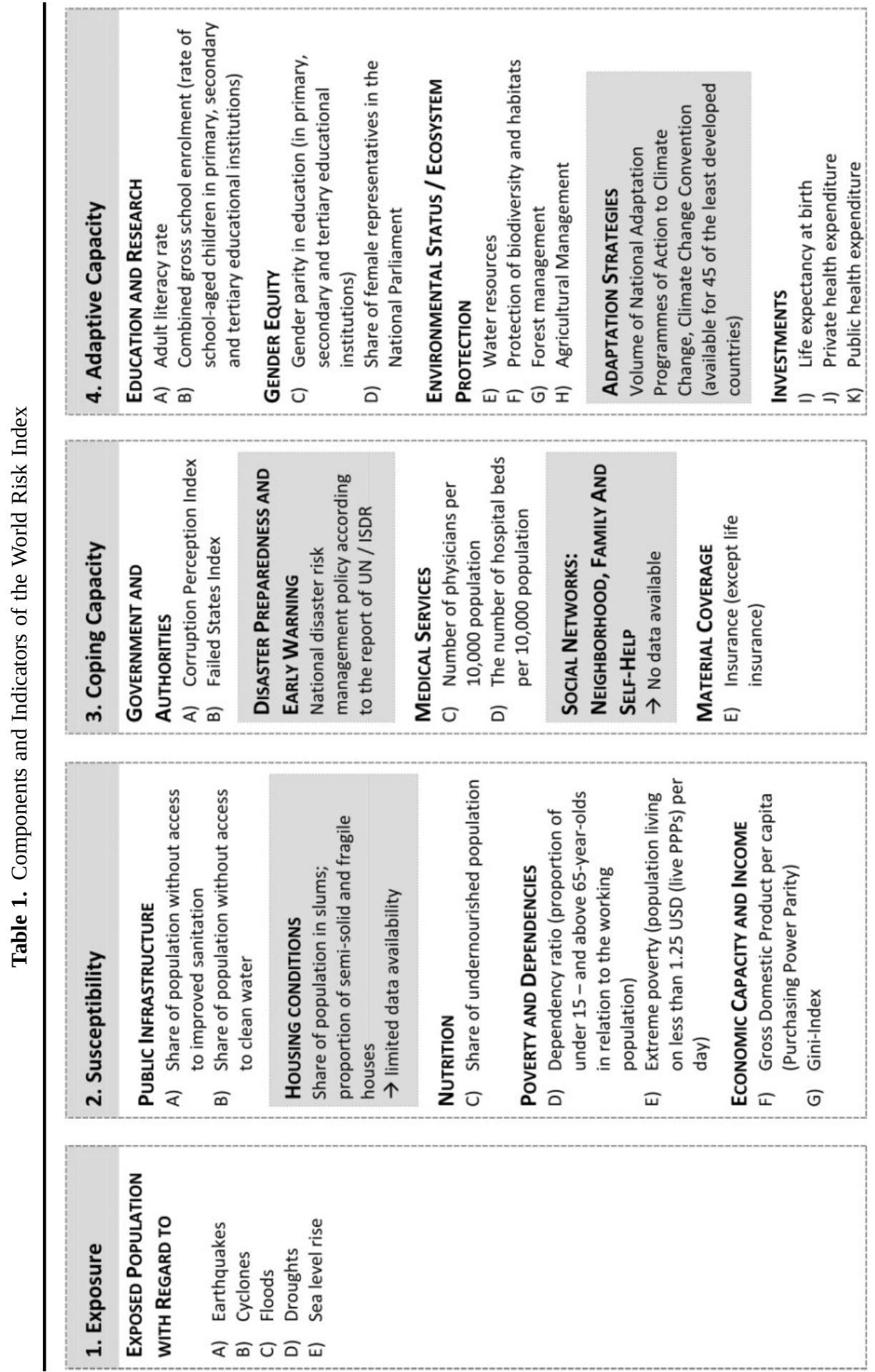


Table 2. Component and Indicators of the WRI Linked to Respective SGDs

\begin{tabular}{|c|c|c|c|}
\hline WRI-Component & & WRI-Indicator(s) & SDG Goal \\
\hline $\begin{array}{l}\text { usceptibility: Public } \\
\text { Infrastructure }\end{array}$ & (A) & $\begin{array}{l}\text { Share of population without } \\
\text { access to improved sanita- } \\
\text { tion } \\
\text { Share of population without } \\
\text { access to clean water }\end{array}$ & $\begin{array}{l}\text { No. 6: Ensure access to water and san- } \\
\text { itation for all }\end{array}$ \\
\hline Susceptibility: Nutrition & (C) & $\begin{array}{l}\text { Share of undernourished } \\
\text { population }\end{array}$ & $\begin{array}{l}\text { No. 2: End hunger, achieve food secu- } \\
\text { rity and improved nutrition and } \\
\text { promote sustainable agriculture }\end{array}$ \\
\hline $\begin{array}{l}\text { usceptibility: Poverty } \\
\text { and dependencies }\end{array}$ & $\begin{array}{l}\text { (D) } \\
\text { (E) }\end{array}$ & $\begin{array}{l}\text { Dependency ratio } \\
\text { Extreme poverty (population } \\
\text { living on less than } 1.25 \\
\text { USD) }\end{array}$ & $\begin{array}{l}\text { No. 8: Promote inclusive and sustain- } \\
\text { able economic growth, employment } \\
\text { and decent work for all } \\
\text { No. 1: End poverty in all its forms } \\
\text { everywhere }\end{array}$ \\
\hline $\begin{array}{l}\text { usceptibility: Economic } \\
\text { Capacity and Income }\end{array}$ & $\begin{array}{l}\text { (F) } \\
\text { (G) }\end{array}$ & $\begin{array}{l}\text { Gross Domestic Product per } \\
\text { capita } \\
\text { Gini Index }\end{array}$ & $\begin{array}{l}\text { No. 1: End poverty in all its forms } \\
\text { everywhere } \\
\text { No. 8: Promote inclusive and sustain- } \\
\text { able economic growth, employment } \\
\text { and decent work for all } \\
\text { No. 10: Reduce inequality within and } \\
\text { among countries }\end{array}$ \\
\hline $\begin{array}{l}\text { oping Capacity: Gov- } \\
\text { ernment and Authori- } \\
\text { ties }\end{array}$ & $\begin{array}{l}\text { (A) } \\
\text { (B) }\end{array}$ & $\begin{array}{l}\text { Corruption Perception Index } \\
\text { Failed State Index }\end{array}$ & $\begin{array}{l}\text { No. 16: Promote peaceful and inclusive } \\
\text { societies for sustainable develop- } \\
\text { ment, provide access to justice for all } \\
\text { and build effective, accountable and } \\
\text { inclusive institutions at all levels }\end{array}$ \\
\hline $\begin{array}{l}\text { Coping Capacity: Medical } \\
\text { Services }\end{array}$ & $\begin{array}{l}\text { (C) } \\
\text { (D) }\end{array}$ & $\begin{array}{l}\text { Number of physicians per } \\
10,000 \\
\text { Number of hospital beds per } \\
10,000\end{array}$ & $\begin{array}{l}\text { No. 3: Ensure healthy lives and promote } \\
\text { well-being for all at all ages }\end{array}$ \\
\hline $\begin{array}{l}\text { Adaptive Capacity: Edu- } \\
\text { cation and Research }\end{array}$ & $\begin{array}{l}\text { (A) } \\
\text { (B) }\end{array}$ & $\begin{array}{l}\text { Adult literacy rate } \\
\text { Combined gross enrolment } \\
\text { ratio }\end{array}$ & $\begin{array}{l}\text { No. 4: Ensure inclusive and quality } \\
\text { education for all and promote life- } \\
\text { long learning }\end{array}$ \\
\hline $\begin{array}{l}\text { Adaptive Capacity: Gen- } \\
\text { der Equity }\end{array}$ & $\begin{array}{l}\text { (C) } \\
\text { (D) }\end{array}$ & $\begin{array}{l}\text { Gender parity in education } \\
\text { Women in national parlia- } \\
\text { ment }\end{array}$ & $\begin{array}{l}\text { No. 4: Ensure inclusive and quality } \\
\text { education for all and promote life- } \\
\text { long learning } \\
\text { No. 5: Achieve gender equality and } \\
\text { empower all women and girls }\end{array}$ \\
\hline $\begin{array}{l}\text { Adaptive Capacity: Envi- } \\
\text { ronmental status/Eco- } \\
\text { system protection }\end{array}$ & $\begin{array}{l}\text { (E) } \\
\text { (F) } \\
\text { (G) } \\
\text { (H) }\end{array}$ & $\begin{array}{l}\text { Water resources } \\
\text { Protection of biodiversity } \\
\text { and habitats } \\
\text { Forest management } \\
\text { Agricultural management }\end{array}$ & $\begin{array}{l}\text { No. 15: Sustainably manage forests, } \\
\text { combat desertification, halt and } \\
\text { reverse land degradation, halt } \\
\text { biodiversity loss }\end{array}$ \\
\hline $\begin{array}{l}\text { Adaptive Capacity: } \\
\text { Investments }\end{array}$ & (I) & $\begin{array}{l}\text { Life expectancy at birth } \\
\text { Public health expenditure }\end{array}$ & $\begin{array}{l}\text { No. 3: Ensure healthy lives and promote } \\
\text { well-being for all at all ages }\end{array}$ \\
\hline
\end{tabular}


SDG goals such as SDG 1 "no poverty”, SDG 2 "zero hunger”, 3 "good health and well-being”, etc. are important universal goals, however, the option and possibility to achieve the desired targets in various countries classified as highly vulnerable is very different due to the differential vulnerability and, for example, the persistence of susceptibility in some countries, such as in the Sahel as the WRI results of different years show. Consequently, national targets should better account for existing differences in vulnerability and adaptive capacity levels. The WRI can provide a first information source where countries might belong to a similar group facing same challenges with regard to vulnerability, exposure and risk reduction. In this regard the index could even be used to identify countries which should enhance their exchange due to similar structural challenges when dealing with disaster risk reduction, climate change adaptation and last but not least the implementation of the SDGs.

However, not all SDGs are represented in the WRI and vice versa the SDGs do not cover all indicators used in the WRI, such as the insurance coverage or the exposure to natural hazards.

Overall, all indicators used for the WRI are systematized along the four core components of the index, namely exposure, susceptibility, coping and adaptive capacities (see Welle and Birkmann 2015b for more discussion).

The component exposure captures the population or built-up area and infrastructure that is physically and spatially exposed to one or more natural hazards or extreme events, namely earthquakes, storms, droughts, floods and sea level rise, while the vulnerability with its three components susceptibility, coping capacity and adaptive capacity assesses the conditions of the exposed population, infrastructure, built-up area or ecosystem (see Welle and Birkmann 2015a,b). In this regard, susceptibility as the first sub-component of vulnerability is understood as the likelihood of experiencing harm in case an extreme event or specific natural hazard would strike a certain country or region. Consequently, susceptibility describes structural characteristics and conditions of a society, such as its demographic structure, level of extreme poverty or the level of infrastructure provision for the population. Susceptibility is an inherent characteristic of the system - for example the society exposed - , however, susceptibility is also influenced by external drivers, such as trade systems or regional conflicts. In addition, we believe that people and systems exposed are not only fragile, but also have different capacities to deal with the additional stress during an extreme event, before and thereafter.

In this context, we differentiate between coping and adaptive capacities. While coping capacities comprise various abilities of societies and exposed elements to minimize negative impacts of natural hazards and climate change through direct action and the resources available, adaptive capacities are understood as those 
resources and options that allow to change systems or that allow people to undertake structural changes in the medium- and long run which ensure that people can actually live with the extreme events or natural hazards (see Lavell et al. 2012; Birkmann et al. 2013). That means coping and adaptive capacities often refer to different timescales and contain different foci. While coping capacities are resources that help to deal with the direct consequences of an extreme event or natural hazard, adaptation capacities is interpreted as fundamental resources and capacities that help to undertake structural changes, such as livelihood changes, in order to reduce vulnerability and increase the resilience of a community to natural hazards in the future.

Indicators used for assessing different levels of adaptive capacities within the WRI are for example, the adult literacy rate, gender parity in education or health expenditure and the quality of the environment (e.g., biodiversity and habitat protection). In contrast, coping capacities or in our model the lack of coping capacities are measured for example with indicators such as the governance performance (since fragile and failed states often have no means to help people that are adversely affected by an extreme event) and also insurance coverage as well as medical infrastructures (number of physicians per 10,000 inhabitants as well as the number of hospital beds per 10,000 inhabitants). A detailed overview of the indicators and the weighting factors applied can be found in Birkmann et al. (2011) and Welle and Birkmann (2015b).

The aggregated WRI is calculated by multiplying exposure with vulnerability, since risk is understood as the product of interaction of natural hazards on one hand and the societal or infrastructure or ecosystem vulnerability on the other. In this study we use physical exposure from the Global Risk Data Platform preview, which includes aspects of frequency and intensity of natural hazards. The multiplication of the two aggregated factors (hazard exposure and vulnerability) is needed, since we believe that if a society is not exposed to a natural hazard at all or if a society is not vulnerable to a hazard it means that the risk is zero. In reality all 171 countries assessed show different levels and degrees of exposure and vulnerability.

Overall, the concept used in the WRI is in line with frameworks and models used in Disaster Risk Reduction and Climate Change Adaptation. For example, the identification of key risks and the analysis of the risk reduction potential through different adaptation measures are a core element of the recent IPCC report (AR5) and its assessment (see Mach et al. 2016, pp. 427-444).

The index can provide a first information basis regarding countries in which exposure and vulnerability levels are significantly higher compared to other countries. Hence, the index operates mainly with the notion of a relative exposure and vulnerability that means we compared and assessed countries which are more 
at risk and more vulnerable compared to other countries or country groups. We do not have specific thresholds, such as the thresholds for the different SGDs, we rather identify global hotspots of risk, exposure and vulnerability out of the comparison of the different values and the variance across countries. In this regard it is important to note that such a risk index also encompasses limits. Like any other index, the WRI can only be based on and calculated with indicators for which comparable, quantifiable data is available for 171 countries or more. Important aspects that we would like to include into the composition of our model, such as the strength of social networks or the level of neighborly help, could not be included, since global data is not available for these aspects. In addition, it is problematic to assume that the WRI results can also directly provide an answer regarding the question of appropriate risk reduction measures in specific places. The index provides an overview and hints toward important problems and challenges. For example, countries like Vanuatu, Chad or Haiti, to name a few in different world regions, are not only exposed to natural hazards and high levels of poverty, they at the same time also face significant challenges in terms of limited coping capacities for example due to high levels of corruption and low governance performance. Consequently, the index underscores the multifaceted nature of exposure and vulnerability as well as the complexity of risk reduction challenges.

\section{Key Results 2016}

Due to the fact that no updated data was available regarding the level of exposure compared to the WRI 2015, the changes observed within the different country rankings are determined by changes in vulnerability, namely changes in susceptibility, coping and adaptive capacities. The results shown in Figure 1 for 171 countries underscore that the global hotspots of risk due to a high exposure to natural hazards and high vulnerability levels are found in Oceania, Sub-Saharan Africa, Southeast Asia and Central America and the Caribbean — particularly in Haiti.

When looking at the country rankings in the three vulnerability components, namely susceptibility, lack of coping capacity and lack of adaptive capacities, the index reveals changes for some countries, while other countries seem to be characterized by the persistence of high levels of susceptibility and limited capacities to cope and adapt. Furthermore, changes in some countries need to be interpreted with caution since the data for the sub-category public infrastructure in the component susceptibility as well as the sub-category ecosystem status and ecosystem protection in the component adaptation was slightly modified in this measurement and calculation within the context of the implementation of the 
The WRI 2016

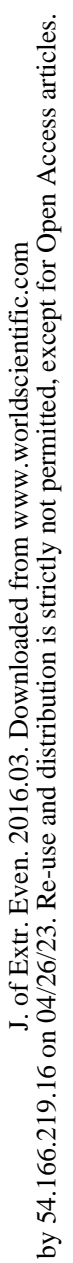

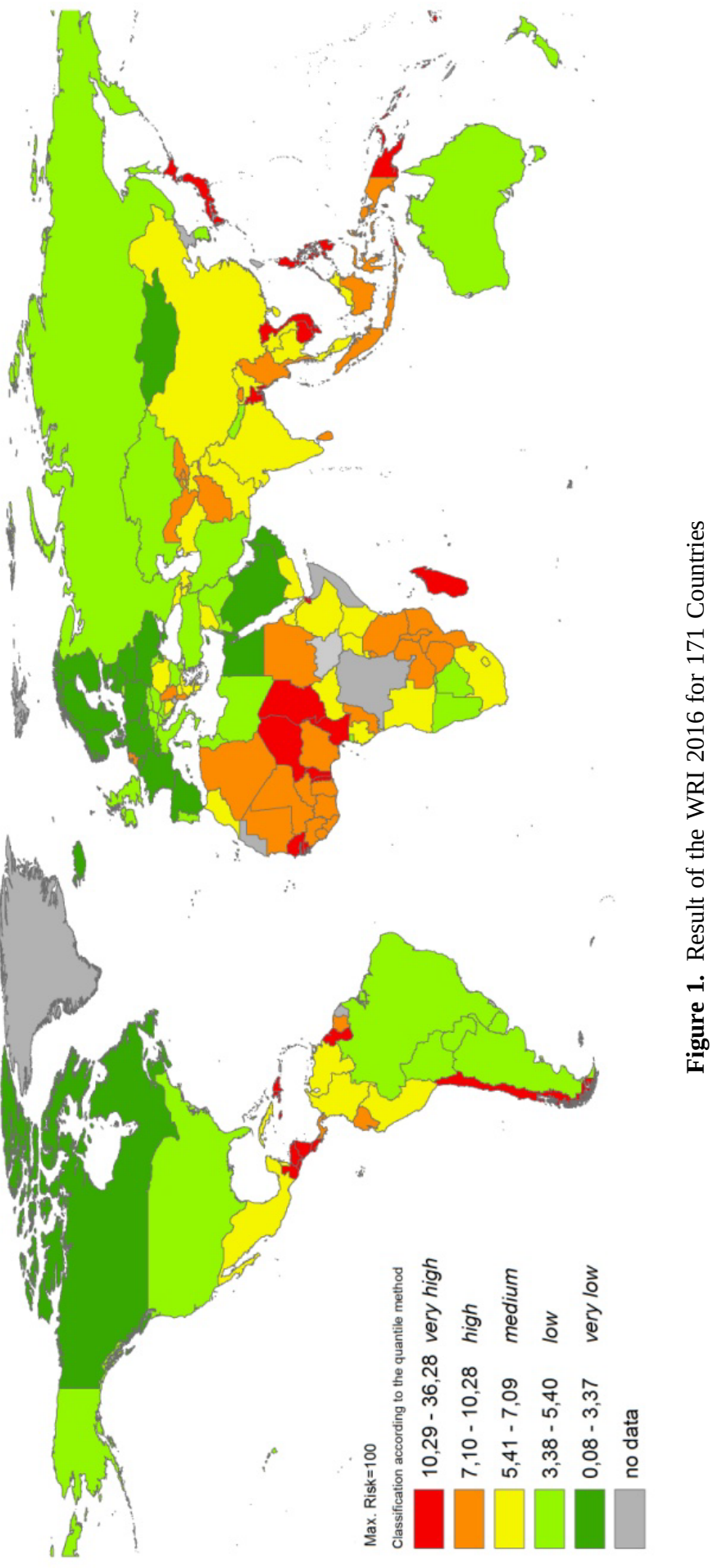

1650005-9 
SDGs. For example, the category agricultural management within the environmental performance index (EPI) 2016 is composed of different input indicators compared to the EPI 2014 (Hsu et al. 2016). Those changes also affect the results of adaptive capacities within the WRI and lead to difficulties in interpreting the changes between 2015 and 2016.

\section{Susceptibility}

In terms of the global assessment of susceptibility, the WRI 2016 confirms again that most countries in the highest category of susceptibility belong to the Sahel and the tropical part of Africa (see Figure 2). Consequently, Africa can be seen as a global hotspot of susceptibility. In addition, Afghanistan, Haiti, Papua New Guinea and East Timor are also among the countries with very high levels of susceptibility. Interestingly, Haiti is the only country among the top 15 countries with the highest susceptibility that is not on the African continent.

Compared to the assessment report in 2015, significant shifts could be observed in terms of Zimbabwe showing an increasing susceptibility, shifting from rank 18 up to rank 13 particularly due to a higher share of people without access to improved water supply and sanitation. Also the percentage of undernourished people has increased significantly from 31.8\% in 2015 to 33.4\% in 2016. Interestingly, we observe a different trend in Malawi: Compared to the WRI results of 2015, the country's susceptibility has decreased and shifted from rank 10 to rank 18 which is a signal for a positive trend.

Reasons for the improvement can be found in an increase in the access to improved water supply and sanitation. However, these shifts partially seem to be linked to improved data.

The most significant negative shift was actually observed in a country outside of Africa. The Lebanon showed a severe increase in susceptibility and shifted 20 ranks from the category very low susceptibility in former years to medium susceptible this year. Important drivers of this development are the military conflicts that also have impacts on the access of people to infrastructure services, such as sanitation. In addition, changes in the demographic structures are evident and lead to increases in susceptibility.

\section{Coping Capacities}

The coping capacities measured in reverse as the lack of coping capacities underscore that hotspots are in Africa and Asia (see Figure 3). Interestingly, changes in the country ranks of coping capacities are determined primarily by governance indicators, namely shifts in corruption perception and good governance. While 
The WRI 2016

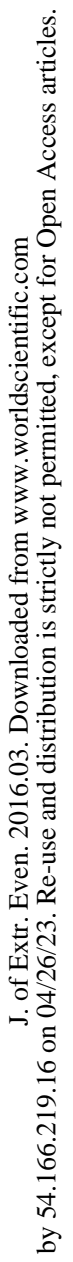

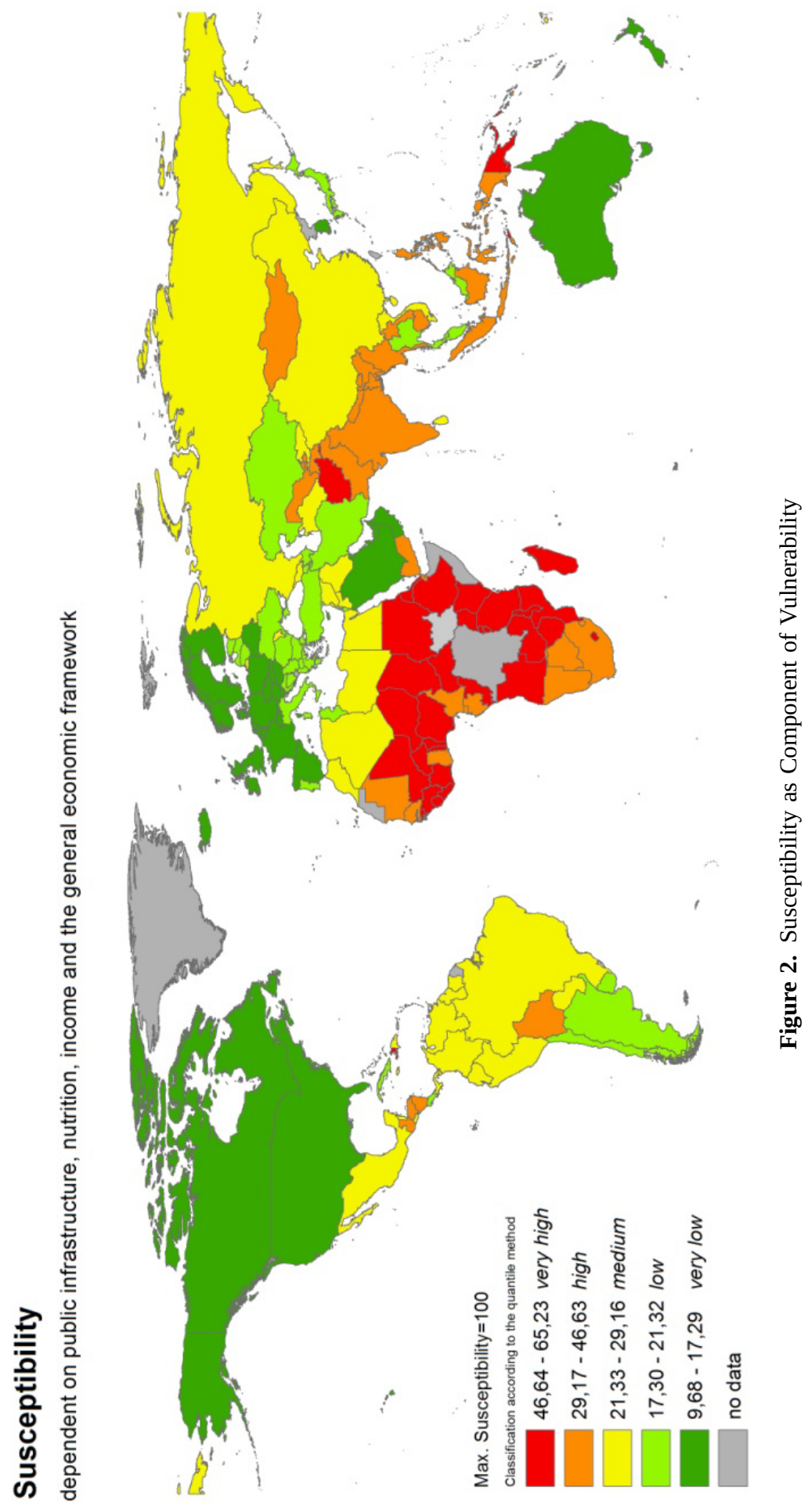


J Birkmann and T Welle

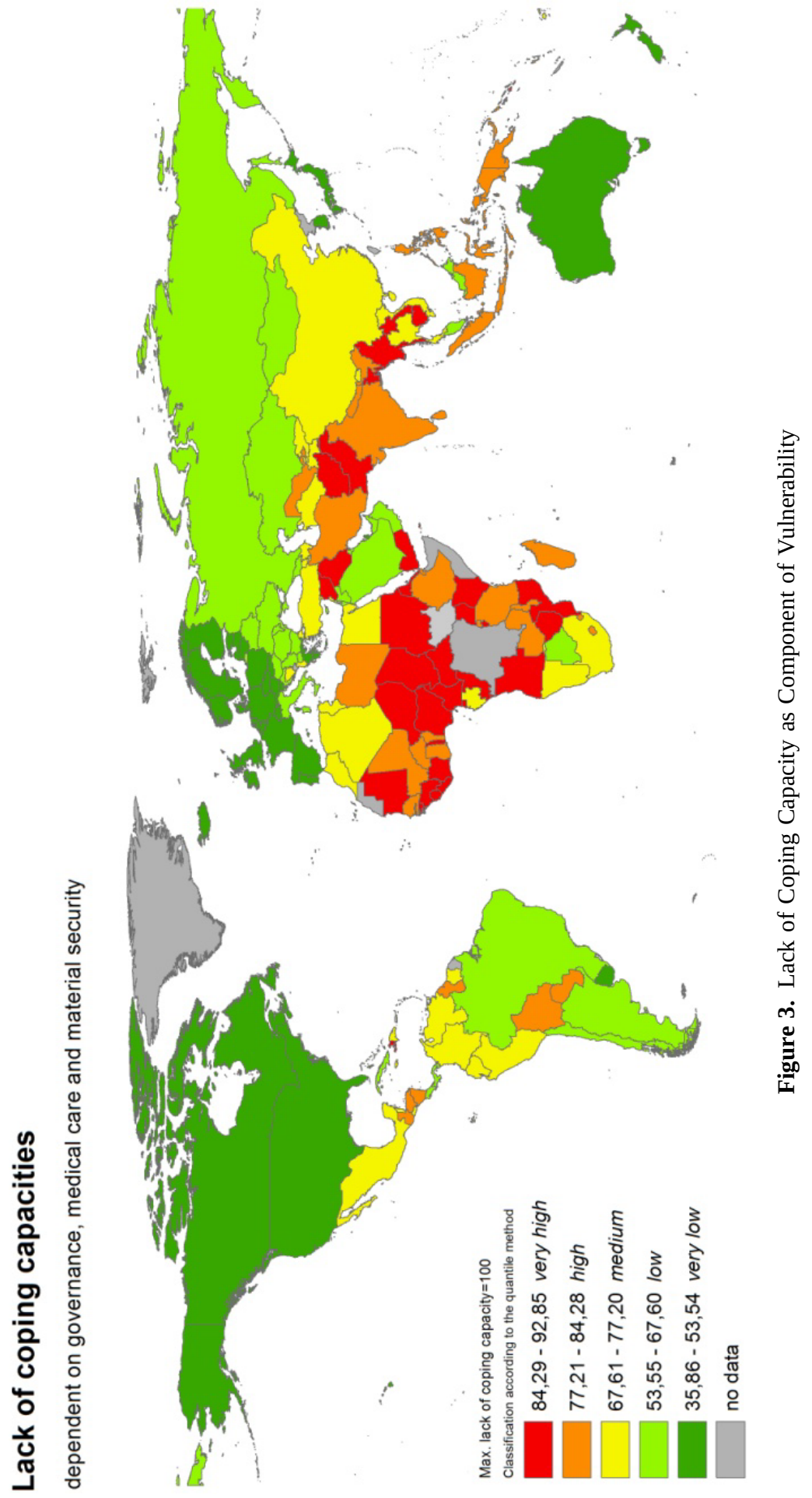


minor shifts between Afghanistan and Sudan are visible in the sense that Afghanistan moved to the first rank and further decreased its performance and stability in terms of governance and corruption, the most significant shift in coping capacities among the 171 countries assessed can be found in Libya and Mali which shifted not only a rank but an entire class within the WRI. For example Syria decreased its performance and shifted 10 ranks toward a higher risk class, particularly due to the catastrophic political situation and the ongoing military conflict in the country. Even though the country is not highly exposed to natural hazards and climate change compared to other countries, it is likely that any occurrence of an intensive drought or flood would most likely have severe consequences due to the instability and the low level of support that people can expect from governmental institution due to the present instability.

\section{Adaptive Capacities}

Hotspots in terms of low adaptive capacities are particularly evident in West Africa and the Sahel region as well as in parts of Southeast Asia. Due to a new calculation method within the EPI that is part of the component adaptive capacities, changes in this component are rather significant. Even though some shifts of countries in their ranking of adaptive capacities might be due to the new calculation method applied for the EPI, such as for Eritrea which increased its lack of adaptive capacity by eight ranks, the analysis reveals (see Figure 4) that particularly the Sahel in Africa can be seen as a global hotspot.

Some countries might be able to increase their adaptive capacity on their own, for example in terms of improvements of the adult literacy rate or the investments in public health care. However, comparing the low coping and adaptive capacities in these countries over the years and the persistence vulnerability it is evident that changing these patterns requires regional strategies and institutions for risk reduction and adaptation. Countries in the Sahel, such as Chad, Sudan, Niger, Mauritania and also Mali show - with some exceptions - very severe limitations in terms of adaptive capacities that restrict adaptation in the medium and long run as well as severe deficiencies in the area of coping capacities.

In terms of the categories coping and adaptive capacities, Chad, Sudan, Niger and Mauritania are all ranked as countries with the highest deficiencies (see Figure 5) - thus in a very high class. Solely Mali is on the borderline in terms of coping capacities between the highest and the second highest class. Consequently, state institutions in these countries are particularly weak or show a low level of performance. That means, risk reduction efforts cannot be effectively developed in these countries or respective local communities, but in our opinion require regional institutions, such as the African Union, to be more pro-active in this 


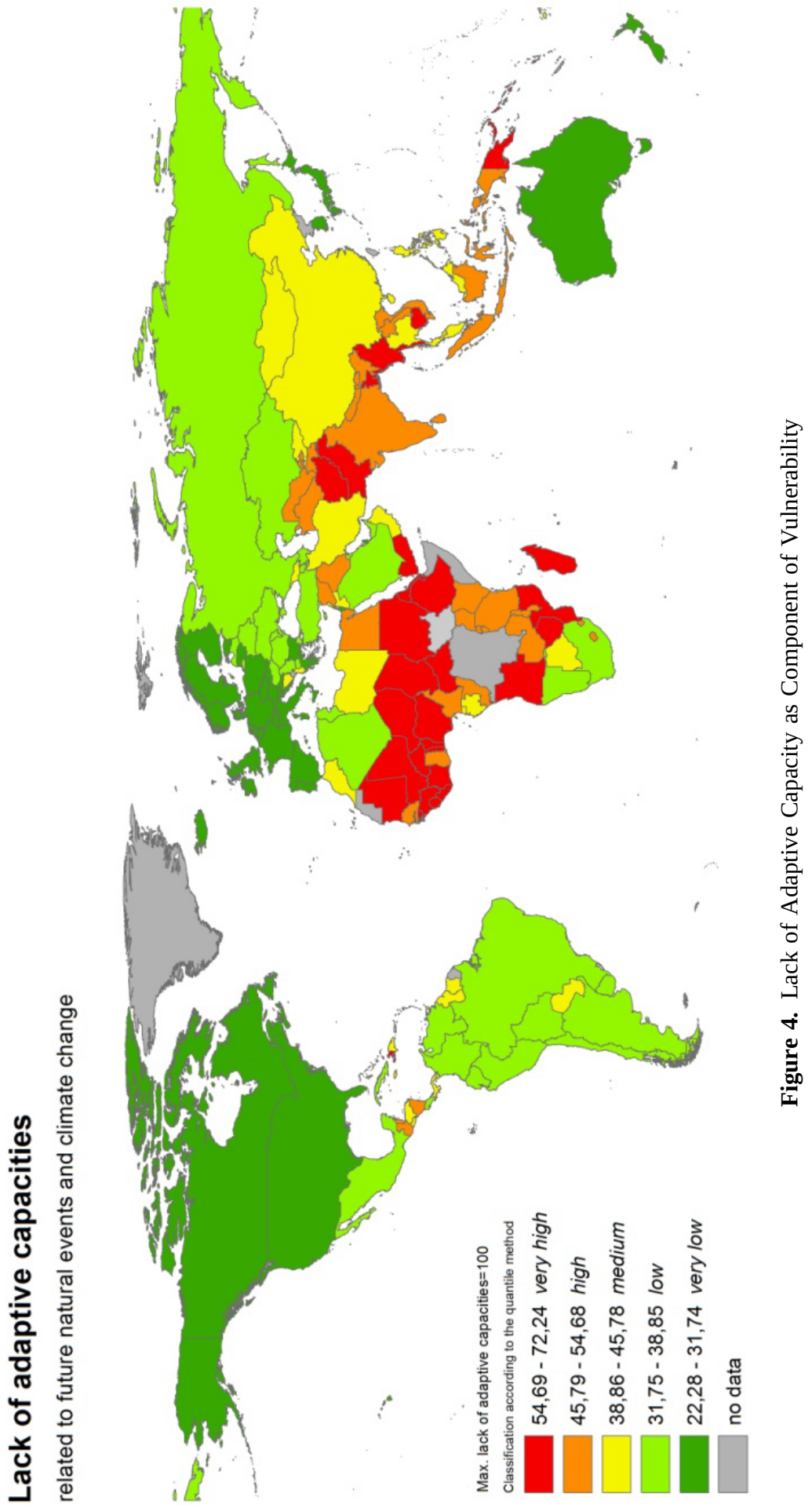




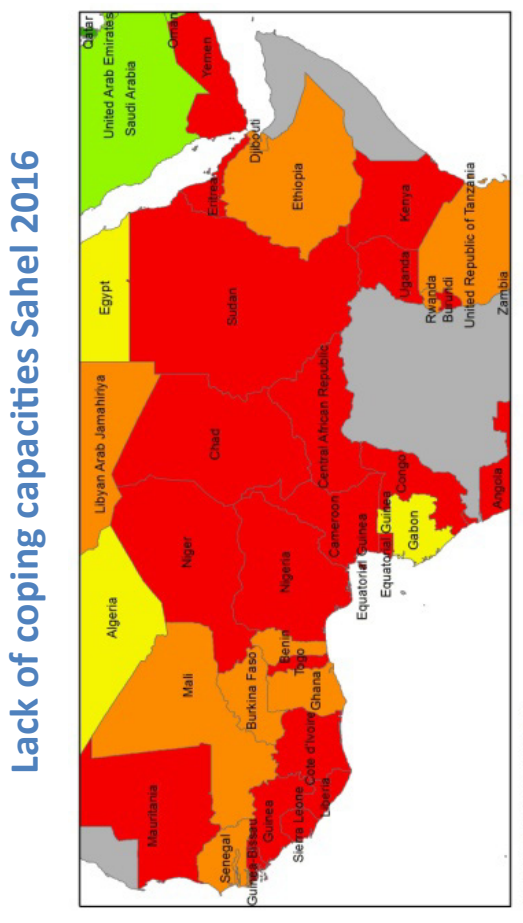

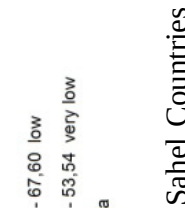

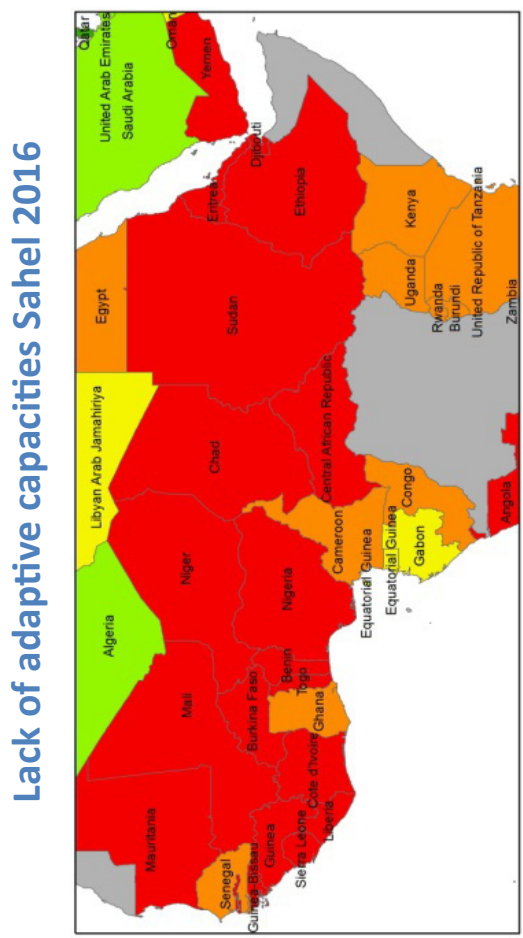

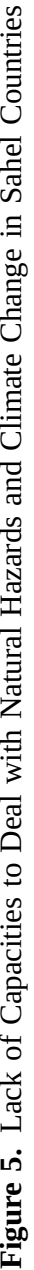




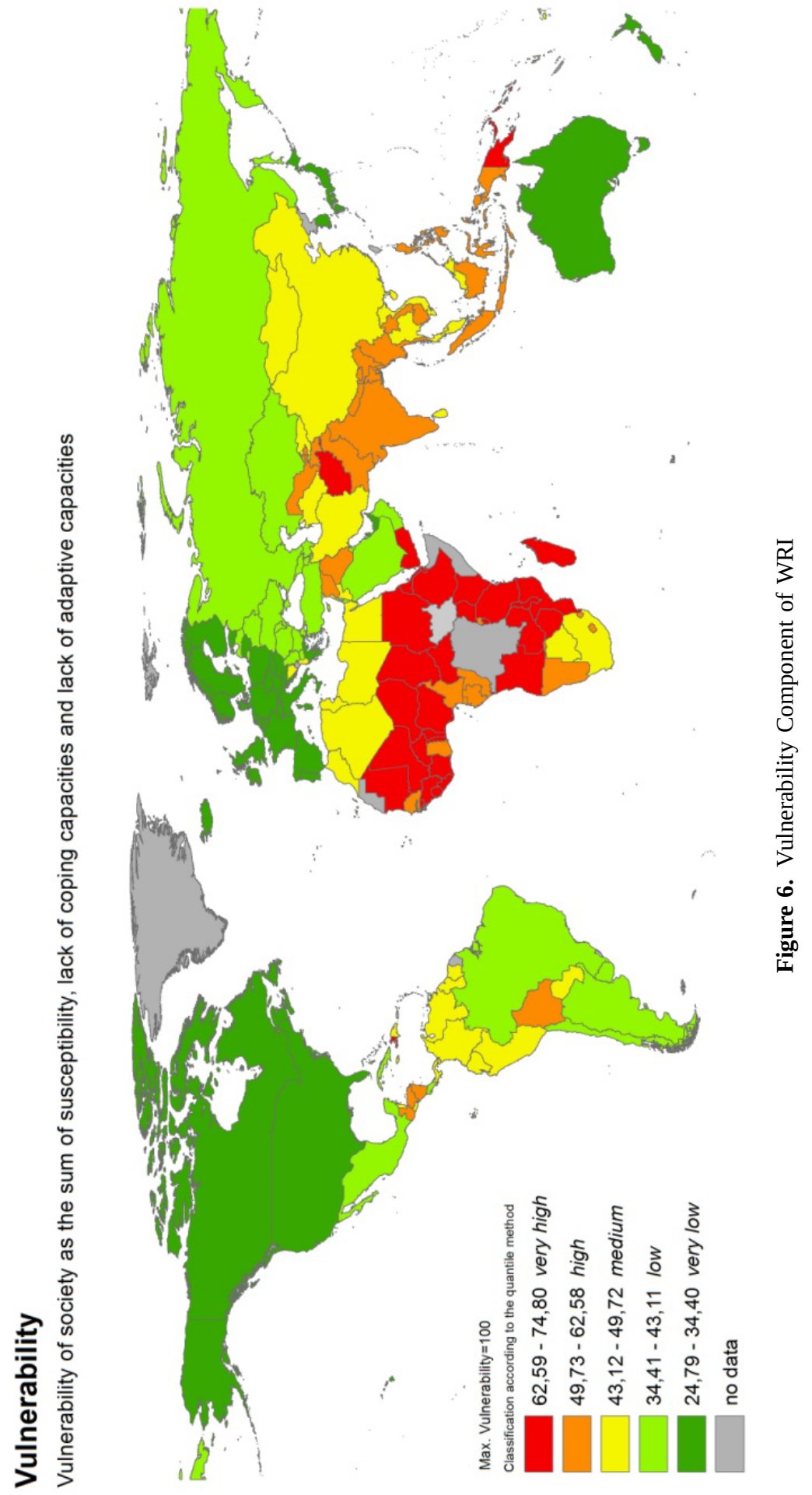


field. Also the prevalence of the high vulnerability in these countries shows that no progress could be achieved so far. This is quite different to countries in Asia and Southeast Asia which could - over the past decades - decrease their vulnerability significantly.

\section{Vulnerability}

The combined results of susceptibility and the lack of coping and adaptive capacities in countries within the vulnerability map (see Figure 6) underscore that the countries with the highest vulnerability are primarily located on the African continent. Haiti and Afghanistan are important exceptions and are among the 15 most vulnerable countries worldwide. Interestingly, Sudan and Zimbabwe are the countries that show even further increases in vulnerability and these countries rank among the top 15 most vulnerable countries worldwide in 2016. However, there are also countries that improved their situation and decreased their vulnerability, such as Paraguay which shifted from the classification of a country with high vulnerability to the class medium vulnerability. This however, has to do with improved data on the adaptive capacity and the modified calculation of the EPI.

Overall, shifts in the calculation of the EPI do not have a significant impact on the ranking of all countries, e.g., Malaysia shifted from the class low vulnerability into the class medium vulnerability due to lower coping capacities although the adaptive capacities are higher compared to 2015.

\section{World Risk Index 2016}

While the spatial distribution of the global risk hotspots such as Oceania, Southeast Asia, Central America and the Sahel remains similar to the results calculated in the former year, significant shifts of a country could be observed for Brunei Darussalam which moved from rank 12 to rank 7 in terms of global risk, particularly due to increases in vulnerability. In contrast, Namibia has improved its situation. The country was able to reduce its vulnerability shifting from a country with medium risk towards a country with low risk in the global comparison, even though the country is exposed to droughts and floods as well as sea-level rise. In Europe, Serbia has shifted from the ranking of medium risk to a country ranking high risk due to a lower performance in the area of governance and due to improved data on adaptive capacities.

\section{The Necessity for Regional Cooperation and Regional Strategies}

When examining the risk profiles and the determinants of risk within the WRI, namely hazard exposure, susceptibility, lack of coping and adaptive capacities, 
countries like Vanuatu, Solomon Islands, Cambodia, as well as the Philippines and Bangladesh are not solely characterized by a very high exposure to extreme events and potential sea-level rise, but at the same time also show severe deficits in coping and adaptive capacities (see Table 3).

Even though reducing exposure to natural hazards will be possible in some countries e.g., in terms of floods, the first entry point to reduce the risk to natural hazards and climate change will be improving preparedness and resilience thus enhancing coping and adaptive capacities and reducing susceptibility. Consequently, more efforts are needed to reduce the prevalent conditions that allow extreme events and hazards to trigger a disaster.

The analysis of countries with the highest vulnerability scores the WRI reveals that the Sahel countries, such as Chad, Niger, Sudan, Mali and Mauritania all face significant challenges regarding susceptibility as well as coping and adaptive capacities (see Table 4).

These countries are not only characterized by a high level of persistent poverty but also by significant governance failures and corruption problems. Moreover, various Sahel countries are most likely not in the position to reduce their susceptibility to climate change and natural hazards significantly or to increase their coping and adaptive capacities by themselves. Approaches to fight corruption and to enhance the performance of governmental institutions, particularly in countries with major governance failures or in so called fragile states might need to be supported or even initiated and supervised by regional institutions due to the existing deficiencies at the national level.

That means when considering the high exposure and vulnerability of coastal countries, in Oceania (Vanuatu, Tonga, Solomon Islands and Fiji) and the Indian Ocean (Papua New Guinea, Philippines) it is worth to explore how regional institutions, like institutions in Oceania or ASEAN in terms of Papua New Guinea and the Philippines could help to support and strengthen interregional cooperation and exchange. Particularly for small island development states fundamental risk reduction strategies, such as planned migration, require agreements at the regional scale.

Also, local institutions and communities might be important actors to trigger changes and improvements. Nevertheless, institutions at the regional level might be needed to provide further incentives and a regional structure for support and exchange on how to effectively increase the capacity of state and local institutions to support people in coping and adapting to extreme events and natural hazards.

Given the magnitude of challenges particularly in countries which are highly exposed and highly susceptible to natural hazards and selected climate change impacts, it is recommendable to explore more precisely options and capacities of regional institutions to promote resilience and to enhance regional cooperation. 


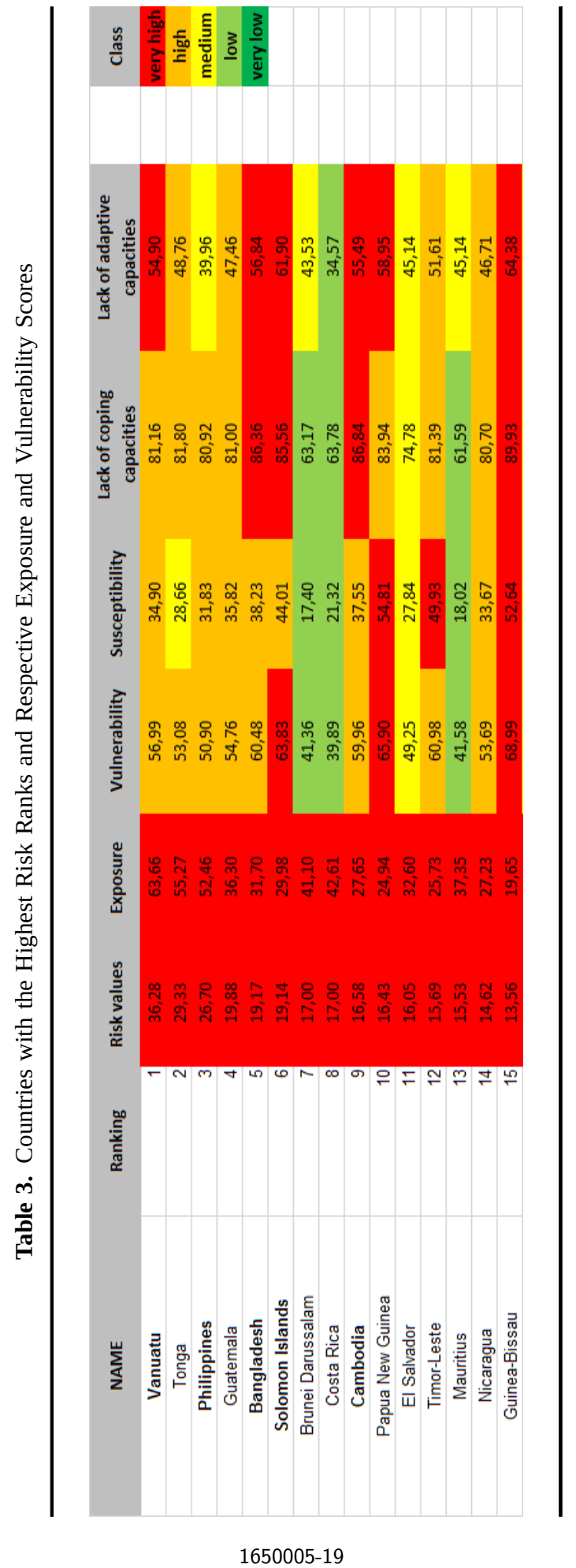




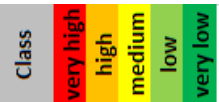

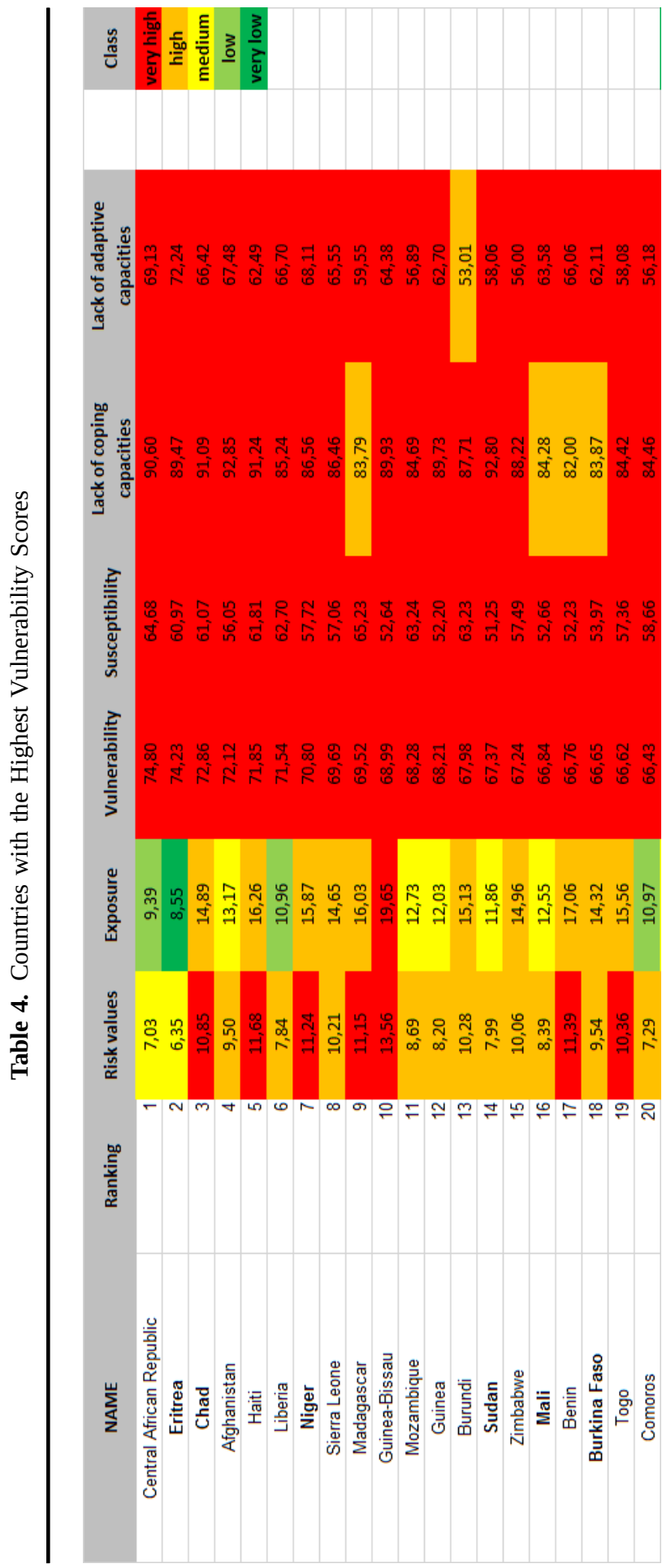


National approaches alone might not be sufficient in countries where the functioning of governmental institutions has proven to be ineffective and in some cases even inexistent in the past. In this regard, the WRI can help to systematically develop different country groupings that require specific regional approaches and that go beyond the conventional classification of countries in terms of their economic capacity (highly developed, medium income, low income, least income countries). The WRI can be a tool to acknowledge and consider the multifaceted nature of risk and vulnerability. Consequently, it should be used to inform decision and policy making in the nexus of sustainable development, climate change adaptation and disaster risk reduction.

\section{References}

Birkmann, J, Welle T, Krause D, Wolfertz J, Suarez D and Setiadi N (2011). World Risk Index: Concept and results. In WorldRiskReport, Berlin: Alliance Development Works, pp. 13-43.

Birkmann, J, Cardona OD, Carreño ML, Barbat AH, Pelling M, Schneiderbauer S, Kienberger S, Keiler M, Alexander D, Zeil P and Welle T (2013). Framing vulnerability, risk and societal responses: The MOVE framework. Nat. Hazards, 67(2), 193-211.

Hsu, A et al. (2016). Environmental Performance Index. New Haven: CT: Yale University. Available at http://www.epi.yale.edu.

Lavell, A, Oppenheimer M, Diop C, Hess J, Lempert R and Li J et al.(2012). Climate change: New dimensions in disaster risk, exposure, vulnerability, and resilience. In Field, C, Barros V, Stocker T, Qin D, Dokken D and Ebi K et al. (eds.) Managing the Risks of Extreme Events and Disasters to Advance Climate Change Adaptation. A Special Report of Working Groups I and II of the Intergovernmental Panel on Climate Change (IPCC), 1st Edition. Cambridge, UK, and New York, NY, USA: Cambridge University Press, pp. 25-64.

Mach, K, Mastrandrea M, Bilir T and Field C (2016). Understanding and responding to danger from climate change: The role of key risks in the IPCC AR5. Climatic Change, 136(3-4), 427-444.

Queiroz de Almeida, L, Welle T and Birkmann J (2016). Disaster risk indicators in Brazil: A proposal based on the worldriskindex. International Journal of Disaster Risk Reduction, 17, 251-272.

UN (United Nations) (2015). Sustainable Development Goals. Sustainabledevelopment.un. org. Available at https://sustainabledevelopment.un.org/topics/sustainabledevelopmentgoals (accessed on 7 July 2016).

Welle, T, Birkmann J and Rhyner J (2014). The WorldRiskIndex 2014. In WorldRiskReport 2014. Berlin: Alliance Development Works, pp. 39-52.

Welle, T and Birkmann J (2015a). The WorldRiskIndex 2015. In WorldRiskReport 2015. Berlin: Alliance Development Works, pp. 41-49.

Welle, T and Birkmann J (2015b). The World Risk Index - An approach to assess risk and vulnerability on a global scale. Journal of Extreme Events, 02(01), 34. doi.org/ 10.1142/s2345737615500037. 